\title{
A Methodology for Long-Term Analysis of Innovative Signalling Systems on Regional Rail Lines
}

\author{
Luca D’Acierno, Marilisa Botte, Claudia Di Salvo, Chiara Caropreso, and Bruno Montella
}

\begin{abstract}
A rail system may be considered a useful tool for reducing vehicular flows on a road system (i.e. cars and trucks), especially in high-density contexts such as urban and metropolitan areas where greenhouse gas emissions need to be abated. In particular, since travellers maximise their own utility, variations in mobility choices can be induced only by significantly improving the level-of-service of public transport. Our specific proposal is to identify the economic and environmental effects of implementing an innovative signalling system (which would reduce passenger waiting times) by performing a cost-benefit analysis based on a feasibility threshold approach. Hence, it is necessary to calculate long-term benefits and compare them with intervention costs. In this context, a key factor to be considered is travel demand estimation in current and future conditions. This approach was tested on a regional rail line in southern Italy to show the feasibility and utility of the proposed methodology.
\end{abstract}

Index Terms-Microscopic rail system simulation, operational cost definition, public transport management, signalling system, travel demand estimation.

\section{INTRODUCTION}

A CCORDING to the European Commission [1], 23.2\% of greenhouse gas emissions in 2014 were produced by the transport sector, of which road transport accounted for $72.8 \%$. The development of actions to promote sustainable transportation systems and to reduce vehicular flows on the road system (i.e. cars and trucks) could therefore significantly abate the sector's emission contributions.

In this context, adoption of a public transport system based on the use of a rail technology which makes railways the highperforming mobility backbone represents a sound choice: besides being environmental friendly, rail systems are highperforming (high travel speeds and low headways), competitive (lower unit costs per seat-km or carried passenger-km) and they are able to ensure a high degree of safety thanks to the presence of signalling, control and train protection systems.

Obviously, the attractiveness of public transport can be

This paper was partly supported under research project FERSAT grant no. PON03PE_00159_4 (Italian Ministry of Education, Universities and Research).

L. D'Acierno (corresponding author), M. Botte, C. Caropreso and B. Montella are with the Department of Civil, Architectural and Environmental Engineering, Federico II University of Naples, via Claudio 21, Naples, 80125 enhanced only by improving service quality and minimising user discomfort. Indeed, since according to the assumptions of rational decision-maker each user tends to choose the alternative of maximum utility (i.e. minimum disutility), the goal is to minimise user generalised costs, which represent the weighted sum of times and monetary costs spent by passengers during their trips. Such costs may be split into: access and egress times, waiting times, travel times, transfer times and ticket costs.

The measures for reducing user generalised cost may be classified according to three main categories: infrastructural measures (new lines or modification of existing lines), fleet improvement (partial or complete replacement of rolling stock) and signalling system modification (replacement or upgrade of trackside and on-board equipment).

Obviously, each kind of intervention affects a specific component of the user generalised cost. Indeed, under the assumption that timetables and all public transport services are integrated and optimised:

- access and egress times depend on the location of stops and stations;

- waiting times depend on the headway between two successive convoys allowed by the travel speed and signalling system adopted;

- travel times depend on rolling stock performance and infrastructure characteristics;

- transfer times depend on the layout of stations, platforms and rolling stock;

- ticket costs depend on pricing policies adopted by administrations.

Clearly, an infrastructural intervention requires high funding availability and may be unfeasible in densely populated contexts. However, in certain cases, it could be essential.

Likewise, the adoption of policies based on replacing existing fleets or reducing fare levels entails increases in national or regional subsidies, which would be difficult to

Italy_email:_luca.dacierno@unina.it; marilisa.botte@unina.it; chiara.caropreso@yahoo.it; bruno.montella@unina.it).

C. Di Salvo is with GE Oil\&Gas, via Cassano 77, Casavatore (Naples), 80020 Italy (email: claudia.disalvo@ge.com). 
achieve in the current economic climate.

Hence the interventions on which to focus concern implementation of innovative signalling systems whose effect is an increase in service frequencies of a rail system and a consequent reduction in passenger waiting times. Moreover, such measures have been made very topical by recent European Union policy whose aim is to create a single European standard for rail networks.

The necessity of the presence of a signalling system lies in the fact that, since the friction between a train wheel (made of steel) and a rail track (also made of steel) imposes stopping distances of several hundred metres (sometimes kilometres), a system solely based on driver visibility is impossible to create. In particular, the safety of a rail system is based on two main aspects: spacing between convoys and train integrity. The former consists in technologically imposing, by means of a signalling system, a minimum distance between two successive trains so that, in the case of the first train slowing or stopping, the following train is able to react and stop safely. The latter consists in verifying the completeness of the train composition while it is in operation.

There are several types of signalling systems currently in use. However, as mentioned above, in order to make rail networks interoperable, the European Union has promoted the development of the European Rail Traffic Management System (ERTMS) [2]. In particular, European Train Control Systems (ETCS), which represent the signalling, control and train protection systems designed to harmonise all European safety systems, can be implemented on four levels: from Level 0 (when an ETCS-compliant rolling stock interacts with a line that is non-ETCS compliant) to Level 3 (when the infrastructure loses any safety and verification function). The higher the implementation level, the higher is the network performance in terms of maximum speed and minimum headway between two successive convoys. In terms of real applications, only Level 2 has been applied in actual railways because on-board train integrity verification is still under research and development (see, for instance, [3]).

In this context, the Italian Ministry of Education, Universities and Research (MIUR) has funded the research project FERSAT whose aim is to develop a rail signalling system based on satellite technologies in order to apply ETCS Level 3. In this regard, we analysed the effects of different rail signalling systems in the case of a regional rail line by performing a costbenefit analysis. However, since the proposed signalling system is based on the ETCS Level 3 paradigm, the achieved results may be easily exported in the case of conventional rail lines, also in the presence of complex nodes.

A key factor to be taken into account for carrying out such an analysis is estimation of travel demand in terms of potential or expected passengers with related characteristics (i.e. starting and arrival stations, adopted time slot, trip duration, etc.). Indeed, such information is essential for any kind of assessment related to transportation systems. This has generated an extensive literature on the estimation and forecasting methodologies of travel demand, which is summarised below.

In general, estimation of current and future demand can be performed by [4]: direct estimation, disaggregated estimation and aggregated estimation. The first approach, indicated in the literature as direct estimation (see, for instance, [5]-[7]), can be adopted to determine only 'present' travel demand. It is based on the application of sampling theory in the case of mobility choices. The main limits of this methodology consist in the vast amount of information to be collected and the inability to predict future developments due to transportation network or socio-economic variations.

The second approach, known as disaggregated estimation (see, for instance, [8]-[11]), consists in specifying (i.e. providing the functional form and related variables), calibrating (i.e. determining numerical values of model parameters) and validating (i.e. verifying the ability of the model to reproduce original data) a model by means of appropriate data. These data express disaggregate information related to a sample of individuals, where the size and sample characteristics generally differ from those used in the first approach. This methodology allows mobility choices to be simulated in current conditions (based on the ability to reproduce sampling data) and in the case of future conditions (based on the ability to simulate user reactions to transportation network or socio-economic variations). The above disaggregated approach is referred to in the literature as the Revealed Preference (RP) approach [4] since it is based on the use of data related to real behaviour of travellers. In the last decades (see, for instance, [12] and [13]), the Stated Preference (SP) approach has been developed, based on the statements of travellers about their appropriately described and designed preferences in hypothetical scenarios. With the use of this second approach the prediction abilities of the calibrated demand models can be improved.

Finally, the last approach, known as aggregated estimation (see, for instance, [14]-[16]), is based on modifying demand model results after correcting them by means of traffic counts (i.e. vehicular or passenger flows). The aim of this approach is to identify an Origin-Destination (OD) matrix which is closest to its estimation by model and, once it is assigned to the network, generates flows closest to the counting data.

Therefore we propose a methodology based on the use of different data sources (censuses, historical data, forecasts, counts, etc.) to estimate travel demand in a wide time period (several decades), so as to perform a cost benefit analysis based on a feasibility threshold approach. Specifically, this assessment concerns the economic and environmental effects of implementing an innovative signalling system, even combined with infrastructural measures which, as we will see, in some cases become imperative in order to make any kind of further intervention effective.

The paper is organised as follows: Section 2 describes the main features of the proposed methodology by focusing on travel demand estimation and investigated performance indexes; Section 3 verifies the usefulness of the proposed approach by applying it in the case of a real regional line; finally, conclusions and research prospects are summarised in Section 4. 


\section{THE PROPOSED METHODOLOGY}

A cost-benefit analysis to estimate economic and environmental utility in modifying the current signalling system on a regional rail line requires the simulation of effects of interactions between all components of a rail system, namely: infrastructure, signalling system, rolling stock, timetable and travel demand. As shown by ([17]-[18]), it is possible to simulate in detail the main aspects of a rail system by resorting to a combination of three kinds of models: a service model for simulating train movements depending on infrastructure, signalling system, rolling stock, planned timetable and travel demand ([19]-[24]); a supply model for simulating performance of all transportation systems in the area depending on passenger flows ([4]); a travel demand model for simulating user choices in terms of mobility selections (departure time, modal choice, starting and arrival stations) and platform behaviour (choices of runs, coaches and entering doors). Details on demand estimation and related interactions with supply models can be found in [25]-[27].

In particular, the whole simulation of the rail system can be performed by using commercial microsimulation software $\left(\right.$ OPENTRACK $^{\circledR}$ software [21]) appropriately integrated with adhoc tools.

As already shown, the main contribution of a new signalling system is reduced passenger waiting times: reduction in headways allows an increase in the number of convoys per hour. Moreover, in certain cases, a different signalling system may also increase travel speeds if they are not limited by infrastructural conditions or close distance between stations.

In light of the above considerations and since our purpose is to implement the methodology by means of a feasibility threshold approach, in the following we do not provide any technological detail concerning the new signalling system, but we characterise it only in terms of maximum achievable performance and maximum level of costs provided.

In particular, in order to evaluate and compare different intervention scenarios within the cost-benefit analysis, it is necessary to simulate effects on travel demand explicitly (by taking into account its variability in a long time horizon) and establish certain evaluation criteria.

The proposed procedure for estimating passenger flows in current and future conditions and the data sources used are set out below, together with the performance indexes adopted.

\section{A. Travel Demand Estimation}

Defining travel demand may be considered of primary importance for evaluating effects of any intervention on transportation systems. However, whatever the methodology adopted, the following requirements have to be met:

- accurate reproduction of the current situation;

- prediction of future conditions arising at least from demographic changes and/or different performance of transportation systems;

- travel demand must be considered a random variable and hence not only average values but also their distribution must be analysed.
This implies that the model has to be elastic at least at the level of modal choice (in the case of transportation system variations) and trip generation (in the case of demographic changes).

Hence, in order to meet these conditions, we propose a methodology based on the use of different Italian data sources, even if generalisations to different contexts may easily be obtained. In particular, the suggested procedure can be divided into seven steps.

The first phase consists in using data from the national census ([28]) which provide revealed information (i.e. related to behaviour actually occurring in the days prior to the survey) concerning mobility choices in terms of origin, destination, daily time period and transport mode. It is worth noting that census data concern systematic trips (i.e. for work or school purposes) during the average working day and origins and destinations are expressed in terms of municipalities. Likewise, daily times are indicated as the morning peak hour (7.30-9.29) and the rest of the day. Moreover, although trips are generally bidirectional (i.e. from home to the workplace and return), these data provide only outward trips. In order to satisfy the third requirement (i.e. a wide distribution of considered values) and increase our dataset, we propose to analyse data from at least two decades (i.e. data from the 2001 and 2011 Italian censuses).

The second phase consists in extending information by means of data from mobility observatories (such as [29]). Indeed, information such as total daily trips, rates of trips during morning peak hours, rates of trip chains (i.e. trips with intermediate destinations) and regional modal split needs to be collected. Indeed, by combining such data, we may generate non-systematic trips during the average working day classified by origin and destination municipality, time period and transport mode used.

In the third phase, by using historical data from the resident population ([30]), previous data may be extended from the census period to a successive period by considering the trip generation model as elastic and adopting a variation rate equal to population variation (i.e. a variation in $\alpha \%$ of population in municipality $A$ provides a variation in $\alpha \%$ of all trips generated in $A$ ).

The following phase consists in generating travel demand matrices related to all-day trips where the origin and destination are the stations of the rail line in question. This means that two sub-phases may be identified: the first for obtaining round trips from outward trips in the case of all-day trips; the second for transforming trips expressed in terms of origin and destination municipalities into origin and destination stations. Obviously, the second sub-phase requires the definition of a regional network model in order to implement a minimum path approach for associating each municipality to each station with suitable assumptions if there are two or more stations in a municipality.

The fifth phase consists in correcting origin-destination matrices associated to rail mode $(r)$ by using turnstile counts, as widely shown in the literature by [14]-[16].

The sixth phase consists in the temporal extension to one or more analysis periods of corrected matrices. In particular, the new matrices may be obtained by considering (real or 
estimated) demographic variations as in the case of the third phase.

In order to make demand elastic at least at modal choice level, it is possible to specify, calibrate and validate a suitable choice model by adopting traditional methodology proposed in the literature (see, for instance, [4]). In particular, it is necessary to:

- $\quad$ specify a utility formulation and a probability choice model;

- calibrate the values of parameters by solving an optimisation problem;

- validate results by means of suitable statistical tests.

The following phase consists in determining hourly matrices consistent with the corrected matrices and data on daily variation in travel demand.

It is worth noting that the above-mentioned procedure makes use of all methodologies previously described for estimating and forecasting travel demand by properly integrating them with each other in a comprehensive theoretical framework. Indeed, recourse to data from national census represents direct estimation of travel demand. In addition, considering three different levels of demographic variation allows us to meet the requirement of stochasticity.

The fifth phase makes use of data from turnstile counts in order to correct the initial Origin-Destination matrices so as to reproduce surveyed flows. Hence, this step addresses the issue of aggregate estimation of travel demand.

Finally, the sixth phase includes both forecasting techniques of travel demand (by means of the temporal extension to future analysis periods of corrected matrices) and its disaggregated estimation (by means of the specification, calibration and validation of a suitable modal choice model).

\section{B. Performance Indexes}

Regarding performance indexes, in order to analyse effects of each intervention scenario, we propose the adoption of an objective function which jointly considers the costs of public administration, passengers and society:

$O F V=N O C+P G C+E C$

The first term is represented by the Net Operational Cost (NOC) which is equal to the part of operational costs not covered by ticket revenues. It can be expressed as follows:

$N O C=T O C-T R$

where TOC is the total operational cost of the rail system and $T R$ is the ticket revenues.

National and regional governments are often inclined to finance public transport in order to improve the mass-transit level-of-service and reduce related fares (i.e. increase user utility). Obviously, there are some regulations for funding public transport. In particular, in Italy, there is a contractual rate (indicated as standard cost) at which the government pays the service company according to transport supply, and a constraint on service effectiveness expressed in terms of the ratio between ticket revenues and operational costs.

Hence, by adopting a standard cost approach, the term TOC can be expressed as:

$T O C=C_{\text {train }-k m} \cdot$ train $-k m$

with:

train $-k m=\sum_{i} \sum_{\Delta t} L_{i} \cdot \varphi_{i, \Delta t} \cdot T_{\Delta t}$

$\sum_{\Delta t} T_{\Delta t}=8,760$ hours $=1$ year

where $C_{\text {train-km }}$ is the standard cost (expressed in Euros per train$\mathrm{km}$ ); train- $\mathrm{km}$ is the unit of measurement adopted to quantify the supply service; $L_{i}$ is the length (expressed in kilometres) of line $i ; \varphi_{i, \Delta t}$ is the service frequency (expressed in trains per hour) of line $i$ during time interval $\Delta t ; T_{\Delta t}$ is duration (expressed in hours) of time interval $\Delta t$.

Ticket Revenues $(T R)$, which depend on fare policies and user choices, can be expressed as follows [31]:

$T R=\sum_{j} \sum_{l} \sum_{\Delta t}\left(t c_{j} / n_{l, j}\right) \cdot f_{l, \Delta t}$

where $t c_{j}$ is the revenue associated to ticket type $j$; $n_{l, j}$ is the number of trips made by user category $l$ by using ticket $j ; f_{l, \Delta t}$ is the passenger flow of category $l$ during time interval $\Delta t$.

The second term is the Passenger Generalised Cost (PGC), which can be expressed as follows:

$P G C=R P G+M T P C+R C$

where $R P G$ is passenger cost on the analysed rail system, $M T P C$ is passenger cost on mass-transit systems except the analysed rail system and $R C$ is user cost on the road system. In particular:

$R P G=T_{a e}+T_{w}+T_{o b}+T_{t}+C_{m}$

$M T P C=T_{a e}+T_{w}+T_{o b}+T_{t}+C_{m}$

$R C=T_{o b}+T_{w}+C_{m}$

where $T_{a e}$ is the access and egress time, $T_{w}$ is the waiting time, $T_{o b}$ is the on-board time, $T_{t}$ is the transfer time and $C_{m}$ is the monetary cost.

In the case of the road system, the on-board and waiting times represent, respectively, times spent travelling along road links and waiting at intersections or searching for parking. However, details on the formulation of the above times can be found in [4] and [32].

Finally, the third term is the Environmental Cost (EC) 
associated to the whole transportation system. It can be formulated as proposed by [32], that is:

$$
E C=e c_{k m} \cdot \sum_{\Delta t} \sum_{a} f c_{a, \Delta t} \cdot L_{a}
$$

where $e c_{k m}$ is the environmental cost (expressed in Euros per kilometre) associated to each vehicle in the road system (i.e. car or truck), $f c_{a, \Delta t}$ is the traffic flow associated to road link $a$ during time interval $\Delta t$, and $L_{a}$ is the length (expressed in kilometres) of road link $a$.

In particular, the implementation of different signalling systems allows different headways to be adopted between two successive trains, which results in an increase in service frequencies. Hence, it is possible to have an increase in total operational costs (TOC), a reduction in passenger waiting times $\left(T_{w}\right)$, an increase in passenger flows on the rail system (which allows an increase in ticket revenues $T R$ ) and a reduction in traffic flows on the road system (which allows a reduction in environmental costs). Obviously, it is necessary to verify quantitatively any compensation between increases and reductions.

\section{APPliCATION IN THE CASE OF A REgiONAL RAIL LinE}

In order to verify the feasibility and the utility of the proposed approach, we applied it to the Naples-Sorrento regional rail line serving the metropolitan area of Naples in southern Italy (see Fig. 1). The line connects the regional capital (i.e. Naples) with the Sorrento peninsula, where the city of Sorrento represents the line terminus.

The line can be decomposed into a first part, $24.5 \mathrm{~km}$ long, between Naples and Moregine, based on a double-track framework and a second part, $17.0 \mathrm{~km}$ long, between Moregine and Sorrento, based on a single-track framework.

Moreover, in Barra and Torre Annunziata there are the junctions respectively for Sarno and Poggiomarino. Hence, between Naples and Torre Annunziata there is the overlap among the different lines.

Since the average distance between successive stations is about $1.2 \mathrm{~km}$ and the maximum acceleration and deceleration is fixed by comfort conditions (i.e. higher values may cause standing passengers to fall over), increases in the maximum speed of lines do not provide significant reductions in travel times. Hence, improvements due to signalling systems are mainly related to reductions in headways between two successive rail convoys which mean reductions in passenger waiting times.

However, it should be pointed out that in the current framework of the line, the existence of a single-track section represents the real bottleneck of the line operation for any possible improvement. Hence, although in a highly populated area such as the analysed contexts (where the average density is 2,631 inhabitants $/ \mathrm{km}^{2}$ ) any infrastructural intervention may require considerable funds, doubling the line, which would cost about $€ 300-800 \mathrm{M}$, represents a major intervention for optimising the benefits of a new signalling system.

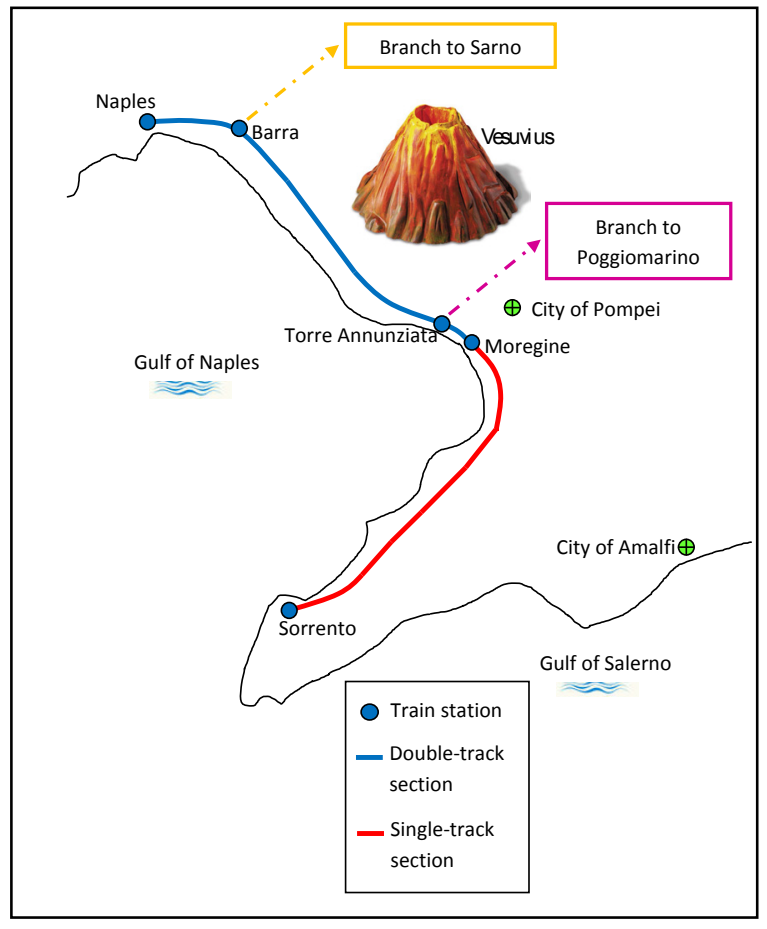

Fig. 1. General framework of the Naples-Sorrento regional rail line.

TABLE I

SCENARIOS ANALYSED

\begin{tabular}{|c|c|}
\hline Scenario & Description \\
\hline 1 & $\begin{array}{l}\text { Current infrastructure; current signalling system; current } \\
\text { timetable. }\end{array}$ \\
\hline 2 & $\begin{array}{l}\text { Current infrastructure; current signalling system; current } \\
\text { timetable for overlapping lines; maximising frequency for } \\
\text { Naples-Sorrento line. }\end{array}$ \\
\hline 3 & $\begin{array}{l}\text { Current infrastructure; current signalling system; maximising } \\
\text { frequency for Naples-Sorrento line, considering it a priority } \\
\text { over other overlapping lines. }\end{array}$ \\
\hline 4 & $\begin{array}{l}\text { Current signalling system; doubling of } \\
\text { Moregine-Sorrento section; current timetable for } \\
\text { overlapping lines; maximising frequency for Naples- } \\
\text { Sorrento line. }\end{array}$ \\
\hline 5 & $\begin{array}{l}\text { Current signalling system; doubling of } \\
\text { Moregine-Sorrento section; maximising frequency for } \\
\text { Naples-Sorrento line, considering it a priority over other } \\
\text { overlapping lines. }\end{array}$ \\
\hline 6 & $\begin{array}{l}\text { Doubling of Moregine-Sorrento section; innovative } \\
\text { signalling system which allows a } 4 \text { minute headway to be } \\
\text { achieved between two successive rail convoys; maximising } \\
\text { frequency for Naples-Sorrento line, considering it a priority } \\
\text { over other overlapping lines. }\end{array}$ \\
\hline 7 & $\begin{array}{l}\text { Doubling of Moregine-Sorrento section; innovative } \\
\text { signalling system which allows a } 3 \text { minute headway to be } \\
\text { achieved between two successive rail convoys; maximising } \\
\text { frequency for Naples-Sorrento line, considering it a priority } \\
\text { over other overlapping lines. }\end{array}$ \\
\hline 8 & $\begin{array}{l}\text { Doubling of Moregine-Sorrento section; innovative } \\
\text { signalling system which allows a } 2 \text { minute headway to be } \\
\text { achieved between two successive rail convoys; maximising } \\
\text { frequency for Naples-Sorrento line, considering it a priority } \\
\text { over other overlapping lines. }\end{array}$ \\
\hline
\end{tabular}

In the above context, we considered the current situation of the line (Scenario 1) and seven additional scenarios of increasing complexity in terms of technological and monetary 
effort. Details of the scenarios analysed are summarised in Table I.

TABLE II

OBJECTIVE FUNCTION VALUES (OFVs) - YEAR 2016

\begin{tabular}{cccc}
\hline \hline \multirow{2}{*}{ Scenario } & \multicolumn{3}{c}{ Objective Function Value } \\
& Minimum & Average & Maximum \\
\hline 1 & $21,612,206$ & $26,001,375$ & $30,390,544$ \\
2 & $21,562,321$ & $25,966,660$ & $30,371,000$ \\
3 & $21,556,056$ & $25,962,951$ & $30,369,845$ \\
4 & $21,350,117$ & $25,822,162$ & $30,294,208$ \\
5 & $21,181,881$ & $25,694,677$ & $30,207,474$ \\
6 & $21,005,063$ & $25,557,593$ & $30,110,123$ \\
7 & $20,363,535$ & $25,030,696$ & $29,697,858$ \\
8 & $18,136,387$ & $22,935,558$ & $27,734,729$ \\
\hline \hline
\end{tabular}

TABLE III

OBJECTIVE FunCTION VALUES (OFVS) - YEAR 2026

\begin{tabular}{cccc}
\hline \hline \multirow{2}{*}{ Scenario } & \multicolumn{3}{c}{ Objective Function Value } \\
& Minimum & Average & Maximum \\
\hline 1 & $20,902,096$ & $25,470,409$ & $30,150,743$ \\
2 & $20,857,177$ & $25,438,469$ & $30,132,151$ \\
3 & $20,851,346$ & $25,434,976$ & $30,131,060$ \\
4 & $20,659,078$ & $25,301,345$ & $30,057,672$ \\
5 & $20,499,187$ & $25,178,209$ & $29,972,295$ \\
6 & $20,330,619$ & $25,045,435$ & $29,876,295$ \\
7 & $19,716,293$ & $24,533,087$ & $29,468,742$ \\
8 & $17,574,679$ & $22,488,373$ & $27,524,045$ \\
\hline \hline
\end{tabular}

TABLE IV

OBJECTIVE FUNCTION VALUES (OFVs) - YEAR 2036

\begin{tabular}{cccc}
\hline \hline \multirow{2}{*}{ Scenario } & \multicolumn{3}{c}{ Objective Function Value } \\
& Minimum & Average & Maximum \\
\hline 1 & $19,878,911$ & $24,640,361$ & $29,653,055$ \\
2 & $19,841,150$ & $24,612,758$ & $29,636,438$ \\
3 & $19,835,943$ & $24,609,605$ & $29,635,479$ \\
4 & $19,663,374$ & $24,487,163$ & $29,566,759$ \\
5 & $19,515,507$ & $24,370,825$ & $29,484,199$ \\
6 & $19,358,826$ & $24,244,789$ & $29,391,002$ \\
7 & $18,783,695$ & $23,755,185$ & $28,993,229$ \\
8 & $16,765,324$ & $21,789,297$ & $27,086,785$ \\
\hline \hline
\end{tabular}

TABLE V

OBJECTIVE FunCTION VALUES (OFVs) - YEAR 2046

\begin{tabular}{cccc}
\hline \hline \multirow{2}{*}{ Scenario } & \multicolumn{3}{c}{ Objective Function Value } \\
& Minimum & Average & Maximum \\
\hline 1 & $18,535,015$ & $23,484,308$ & $28,845,225$ \\
2 & $18,506,654$ & $23,462,747$ & $28,831,814$ \\
3 & $18,502,268$ & $23,460,065$ & $28,831,068$ \\
4 & $18,355,572$ & $23,353,207$ & $28,769,925$ \\
5 & $18,223,498$ & $23,246,337$ & $28,691,938$ \\
6 & $18,082,430$ & $23,129,687$ & $28,603,290$ \\
7 & $17,558,779$ & $22,671,758$ & $28,221,393$ \\
8 & $15,702,281$ & $20,815,657$ & $26,377,041$ \\
\hline \hline
\end{tabular}

TABLE VI

OBJECTIVE FunCTION VALUES (OFVs) - YeAR 2056

\begin{tabular}{cccc}
\hline \hline \multirow{2}{*}{ Scenario } & \multicolumn{3}{c}{ Objective Function Value } \\
& Minimum & Average & Maximum \\
\hline 1 & $16,869,305$ & $21,984,231$ & $27,695,675$ \\
2 & $16,852,596$ & $21,970,508$ & $27,686,826$ \\
3 & $16,849,226$ & $21,968,439$ & $27,686,385$ \\
4 & $16,734,599$ & $21,881,802$ & $27,636,024$ \\
5 & $16,622,100$ & $21,787,218$ & $27,564,543$ \\
6 & $16,500,384$ & $21,682,746$ & $27,482,370$ \\
7 & $16,040,541$ & $21,265,919$ & $27,123,063$ \\
8 & $14,384,679$ & $19,552,276$ & $25,367,067$ \\
\hline \hline
\end{tabular}

The simulation outcome in terms of objective function values in the analysed time period, detailed for minimum, average and maximum levels of demographic variation, is set out below (Tables II-VI).

TABLE VII

OBJECTIVE FUNCTION VARIATIONS - YEAR 2016

\begin{tabular}{cccc}
\hline \hline \multirow{2}{*}{ Scenario } & \multicolumn{3}{c}{ Objective Function Variation } \\
& Minimum & Average & Maximum \\
\hline 1 & - & - & - \\
2 & $-0.06 \%$ & $-0.14 \%$ & $-0.23 \%$ \\
3 & $-0.07 \%$ & $-0.16 \%$ & $-0.26 \%$ \\
4 & $-0.32 \%$ & $-0.74 \%$ & $-1.21 \%$ \\
5 & $-0.60 \%$ & $-1.26 \%$ & $-1.99 \%$ \\
6 & $-0.92 \%$ & $-1.81 \%$ & $-2.81 \%$ \\
7 & $-2.28 \%$ & $-3.93 \%$ & $-5.78 \%$ \\
8 & $-8.74 \%$ & $-12.20 \%$ & $-16.08 \%$ \\
\hline \hline
\end{tabular}

TABLE VIII

OBJECTIVE FUNCTION VARIATIONS - YEAR 2026

\begin{tabular}{cccc}
\hline \hline \multirow{2}{*}{ Scenario } & \multicolumn{3}{c}{ Objective Function Variation } \\
& Minimum & Average & Maximum \\
\hline 1 & - & - & - \\
2 & $-0.06 \%$ & $-0.13 \%$ & $-0.21 \%$ \\
3 & $-0.07 \%$ & $-0.15 \%$ & $-0.24 \%$ \\
4 & $-0.31 \%$ & $-0.71 \%$ & $-1.16 \%$ \\
5 & $-0.59 \%$ & $-1.22 \%$ & $-1.93 \%$ \\
6 & $-0.91 \%$ & $-1.77 \%$ & $-2.73 \%$ \\
7 & $-2.26 \%$ & $-3.87 \%$ & $-5.67 \%$ \\
8 & $-8.71 \%$ & $-12.11 \%$ & $-15.92 \%$ \\
\hline \hline
\end{tabular}

TABLE IX

OBJECTIVE FUNCTION VARIATIONS - YEAR 2036

\begin{tabular}{cccc}
\hline \hline \multirow{2}{*}{ Scenario } & \multicolumn{3}{c}{ Objective Function Variation } \\
& Minimum & Average & Maximum \\
\hline 1 & - & - & - \\
2 & $-0.06 \%$ & $-0.12 \%$ & $-0.19 \%$ \\
3 & $-0.06 \%$ & $-0.13 \%$ & $-0.22 \%$ \\
4 & $-0.29 \%$ & $-0.67 \%$ & $-1.08 \%$ \\
5 & $-0.57 \%$ & $-1.16 \%$ & $-1.83 \%$ \\
6 & $-0.88 \%$ & $-1.70 \%$ & $-2.62 \%$ \\
7 & $-2.23 \%$ & $-3.78 \%$ & $-5.51 \%$ \\
8 & $-8.65 \%$ & $-11.96 \%$ & $-15.66 \%$ \\
\hline \hline
\end{tabular}

TABLE X

OBJECTIVE FUNCTION VARIATIONS - YEAR 2046

\begin{tabular}{cccc}
\hline \hline \multirow{2}{*}{ Scenario } & \multicolumn{3}{c}{ Objective Function Variation } \\
& Minimum & Average & Maximum \\
\hline 1 & - & - & - \\
2 & $-0.05 \%$ & $-0.10 \%$ & $-0.15 \%$ \\
3 & $-0.05 \%$ & $-0.11 \%$ & $-0.18 \%$ \\
4 & $-0.26 \%$ & $-0.60 \%$ & $-0.97 \%$ \\
5 & $-0.53 \%$ & $-1.08 \%$ & $-1.68 \%$ \\
6 & $-0.84 \%$ & $-1.60 \%$ & $-2.44 \%$ \\
7 & $-2.16 \%$ & $-3.63 \%$ & $-5.27 \%$ \\
8 & $-8.56 \%$ & $-11.73 \%$ & $-15.28 \%$ \\
\hline \hline
\end{tabular}

TABLE XI

OBJECTIVE FUNCTION VARIATIONS - YEAR 2056

\begin{tabular}{cccc}
\hline \hline \multirow{2}{*}{ Scenario } & \multicolumn{3}{c}{ Objective Function Variation } \\
& Minimum & Average & Maximum \\
\hline 1 & - & - & - \\
2 & $-0.03 \%$ & $-0.06 \%$ & $-0.10 \%$ \\
3 & $-0.03 \%$ & $-0.07 \%$ & $-0.12 \%$ \\
4 & $-0.22 \%$ & $-0.49 \%$ & $-0.80 \%$ \\
5 & $-0.47 \%$ & $-0.95 \%$ & $-1.47 \%$ \\
6 & $-0.77 \%$ & $-1.44 \%$ & $-2.19 \%$ \\
7 & $-2.07 \%$ & $-3.42 \%$ & $-4.91 \%$ \\
8 & $-8.41 \%$ & $-11.40 \%$ & $-14.73 \%$ \\
\hline \hline
\end{tabular}

Furthermore, variations in the objective function value with 
respect to the non-intervention scenario (i.e. Scenario 1) are reported in Tables VII-XI.

Our numerical results point to a common conclusion: it is indispensable to double the line in order to fully exploit the advantages provided by the innovative signalling system. Indeed, as can be seen, in the current infrastructural configuration of the line (i.e. with a section with a single-track framework) timetable optimisation (i.e. Scenarios 2 and 3) provides improvements which are at most equal to $0.26 \%$ in 2016. Then they drop to $0.12 \%$ in 2056 . Moreover, also complete replacement of the signalling system provides results similar to those of Scenario 3, since the major limitation is related to the single-track section. Hence, although doubling the line (Scenarios 4 and 5) provides maximum improvements lower than $2.0 \%$ over the whole examined period, it represents an intervention required to reduce the current minimum headway between two successive rail convoys. Indeed, a new configuration of the line, based on a fully double-track framework, confers benefits from an innovative signalling system (Scenarios 6, 7 and 8) in terms of a reduction in minimum headways, providing maximum improvements between $16.08 \%$ and $14.73 \%$.

The trend of objective function value variations, during the tested period, in the case of an average rate of demographic change, is shown in Fig. 2.

Leaving aside the slightly decreasing pattern, simply due to a reduction in demographic terms, the graph shows, once again, the importance of the doubling intervention in order to take full advantage of implementing the innovative signalling system. Indeed, although the gap between scenarios 2 and 3 (represented respectively by the black and green line) and scenarios 4 and 5 (represented respectively by the red and blue line) appears limited, without the infrastructural intervention of the doubling of the line it would be impracticable to obtain the benefits provided by scenarios 6, 7 and 8 (represented respectively by the orange, brown and dark green line) which show a far higher gap with respect to the other scenarios.

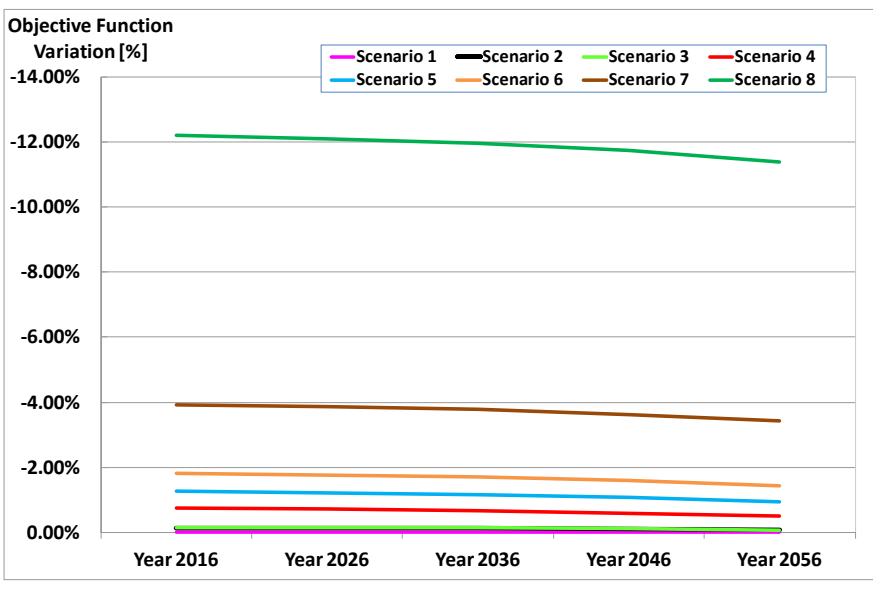

Fig. 2. Variation of objective function value in average conditions during the analysed time period (2016-2056).

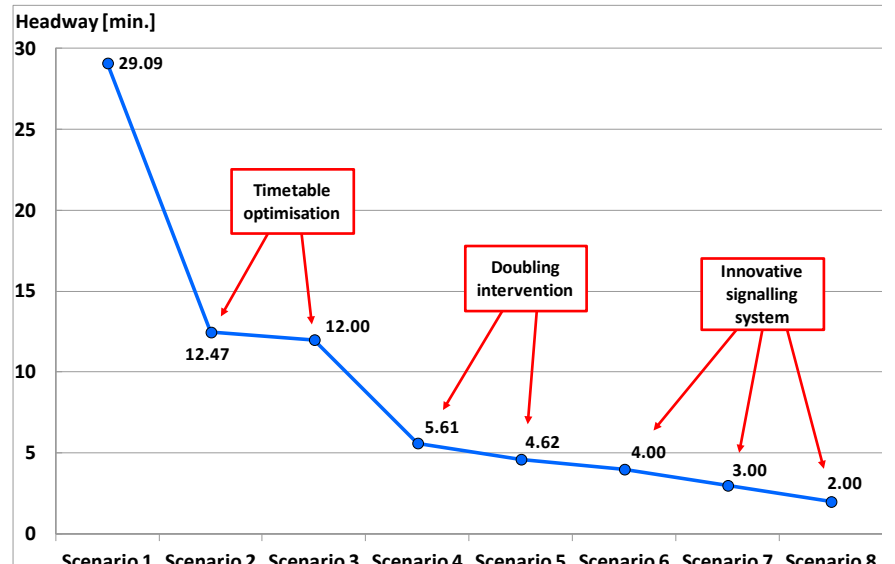

Fig. 3. Simulation results in terms of headway for each scenario analysed.

TABLE XII

NUMBER OF CONVOYS REQUIRED

\begin{tabular}{ccc}
\hline \hline Scenario & Convoys required & Additional convoys \\
\hline 1 & 10 & 0 \\
2 & 19 & 9 \\
3 & 20 & 10 \\
4 & 40 & 30 \\
5 & 49 & 39 \\
6 & 56 & 46 \\
7 & 74 & 64 \\
8 & 110 & 100 \\
\hline \hline
\end{tabular}

Fig. 3 shows the effects of each intervention scenario in terms of the headway between two successive convoys. As can be seen, thanks to timetable optimisation, the headway can be reduced from 29 to 12 minutes, with a reduction of more than $50 \%$; whereas by doubling the line, we can regain only around 7 minutes. However, this infrastructural intervention is essential in order to reduce headways between two successive convoys to as low as 2 minutes.

Obviously, in order to ensure such low headways, it is necessary to put in place an appropriate fleet in terms of number of available convoys per rail service: the lower the headway, the higher the number of trains needed (Table XII).

Hence, besides the above-mentioned costs, additional resources are required to acquire a suitable number of vehicles.

\section{CONCLUSIONS AND RESEARCH PROSPECTS}

The paper proposed a methodology for evaluating economic and environmental effects related to implementing an innovative signalling system by performing a cost-benefit analysis based on a feasibility threshold approach. The application in the case of a real regional rail line shows the usefulness of the proposed procedure and points out that, in the considered context, the main limitation to network improvements is represented by the single-track section. Hence, the replacement of the existing signalling system may be successfully implemented only if combined with doubling of the line.

The costs of infrastructure improvements are clearly high $(€ 300-800 \mathrm{M})$. Yet it is worth noting that they have the same order of magnitude as benefits achievable after just one year. 
A key role in the proposed procedure is represented by the estimation and forecasting techniques for travel demand which is a fundamental factor to consider for evaluating the effects of any intervention in the case of transportation systems. In particular, the suggested methodology makes use of data from Italian sources.

Hence, in terms of future research, we propose to apply the described approach in other contexts both on other Italian railways (in order to verify the correctness of the procedure and, in particular, the reliability of the adopted data sets in different network configurations) and other non-Italian railways (in order to test the methodology in the case of different data sources).

Finally, the main limitation of the proposed approach in the case of more complex rail networks is related to the excessively high number of solutions to be analysed and related computation times. However, recently [33] and [34] have proposed some methodologies based on the use of heuristic and/or meta-heuristic algorithms in order to solve these kinds of problems by reducing computational efforts.

\section{REFERENCES}

[1] European Commission, Climate Action: Reducing emissions from transport.

Available:

http://ec.europa.eu/clima/policies/transport/index_en.htm (last access: September 2016).

[2] J. Pachl, Railway operation and control. VTD Rail Publishing, Mountlake Terrace (WA), USA, 2009.

[3] Shift2Rail Joint Undertaking, Multi-Annual Action Plan. European Union: Brussels, Belgium, 2015.

[4] E. Cascetta, Transportation systems analysis: models and applications. Springer, New York (NY), USA, 2009.

[5] M. J. Smith, "The existence, uniqueness and stability of traffic equilibria," Transportation Research Part B, vol. 13, no. 4, pp. 295-304, 1979.

[6] W. Brog and E. Ampt, "State of the art in the collection of travel behaviour data," in Travel Behaviour for the 1980's, Special Report 201, National Research Council, Washington (DC), USA, 1982.

[7] J. de D. Ortuzar and L. G. Willumsen, Modelling Transport, 4th ed., John Wiley and Sons Ltd., Chichester, United Kingdom, 2011.

[8] T. A. Domencich and D. McFadden, Urban travel demand: a behavioural analysis. American Elsevier, New York (NY), USA, 1975.

[9] J. Horowitz, "Identification and diagnosis of specification errors in the Multinominal Logit Model," Transportation Research Part B, vol. 15, no. 5, pp. 345-360, 1981.

[10] C. F. Manski and D. McFadden, Structural Analysis of discrete data with econometric applications. The MIT Press, Cambridge (MA), USA, 1981.

[11] M. Ben-Akiva and S. R. Lerman, Discrete choice analysis: Theory and application to travel demand. The MIT Press, Cambridge (MA), USA, 1985.

[12] M. Ben-Akiva and T. Morikawa, "Estimation of switching models from revealed preference and stated intention," Transportation Research Part A, vol. 24, no. 6, pp. 485-495, 1990.

[13] J. de D. Ortuzar, "Stated Preference in travel demand modelling," in Proc. WCTR 1992, Lyon, France, 1992.

[14] H. -P. Lo and C. -P. Chan, "Simultaneous estimation of an origin-destination matrix and link choice proportions using traffic counts," Transportation Research Part A, vol. 37, no. 9, pp. 771-788, 2003.

[15] E. Cascetta, A. Papola, V. Marzano, F. Simonelli and I. Vitiello, "Quasi-dynamic estimation of o-d flows from traffic counts: Formulation, statistical validation and performance analysis on real data," Transportation Research Part B, vol. 55, pp. 171-187, 2013.

[16] C. -C. Lu, X. Zhou and K. Zhang, "Dynamic origin-destination demand flow estimation under congested traffic conditions," Transportation Research Part C, vol. 34, pp. 16-37, 2013.

[17] L. D'Acierno, M. Gallo, B. Montella and A. Placido, "The definition of a model framework for managing rail systems in the case of breakdowns," in Proc. IEEE ITSC 2013, The Hague, The Netherlands, pp. 1059-1064, 2013.

[18] L. D'Acierno, A. Placido, M. Botte and B. Montella, "A methodological approach for managing rail disruptions with different perspectives," International Journal of Mathematical Models and Methods in Applied Sciences, vol. 10, pp. 80-86, 2016.

[19] R. Prinz, B. Sewcyk and M. Kettner, "NEMO: Network Evaluation Model for the Austrian railroad (ÖBB)," Eisenbahntechnische Rundschau, vol. 50, no. 3, pp. 117-121, 2001.

[20] M. Kettner and B. Sewcyk, "A model for transportation planning and railway network evaluation," in Proc. WCITS 2002, Chicago (IL), USA, 2002.

[21] A. Nash and D. Huerlimann, "Railroad simulation using OpenTrack," Computers in Railways, vol. 9, pp. 45-54, 2004.

[22] T. Siefer and A. Radtke, "Railway simulation: key for better operation and optimal use of infrastructure," in Proc. 1st International Seminar on Railway Operations Modelling and Analysis, Delft, The Netherlands, 2005.

[23] M. Marinov and J. Viegas, "A mesoscopic simulation modelling methodology for analyzing and evaluating freight train operations in a rail network," Simulation Modelling Practice and Theory, vol. 19, no. 1, pp. 516-539, 2011.

[24] E. Quaglietta, "A microscopic simulation model for supporting the design of railway systems: Development and applications," Ph.D. dissertation, Federico II University of Naples, Naples, Italy, 2011.

[25] G.E. Cantarella, "A general fixed-point approach to multimodal multi-user equilibrium assignment with elastic demand," Transportation Science, vol. 31, no. 2, pp. 107-128, 1997.

[26] S. Nguyen, S. Pallottino and M. Gendreau, "Implicit enumeration of hyperpaths in a logit model for transit networks," Transportation Science, vol. 32 , no. 1, pp. 54-64, 1998.

[27] M. Ercolani, A. Placido, L. D'Acierno and B. Montella, "The use of microsimulation models for the planning and management of metro systems," WIT Transactions on the Built Environment, vol. 135, pp. 509-521, 2014.

[28] Istituto Nazionale di Statistica - ISTAT (Italian National Institute of Statistics). Population and housing census. Available: http://www.istat.it/it/censimento-popolazione (last access: September 2016).

[29] Osservatorio sui comportamenti di mobilità degli italiani - AudiMob (Observatory on the Italian mobility behaviour). Regional mobility statistics. Available: http://www.isfort.it/sito/statistiche/Audimob.htm (last access: September 2016).

[30] Istituto Nazionale di Statistica - ISTAT (Italian National Institute of Statistics). Resident population. Available: http://www.istat.it/it/popolazione (last access: September 2016).

[31] B. Montella, L. D'Acierno and M. Gallo, "A multimodal approach for determining optimal public transport fares," Journal of Applied Sciences, vol. 14, no. 21, pp. 2767-2781, 2014.

[32] M. Gallo, B. Montella and L. D'Acierno, "The transit network design problem with elastic demand and internalisation of external costs: An application to rail frequency optimisation," Transportation Research Part C, vol. 19 , no. 6, pp. 1276-1305, 2011.

[33] L. D'Acierno, M. Gallo and B. Montella, "Application of metaheuristics to large-scale transportation problems," Lecture Notes in Computer Science, vol. 8353, pp. 215-222, 2014.

[34] M. Botte, C. Di Salvo, A. Placido, B. Montella and L. D'Acierno, "A Neighbourhood Search Algorithm for determining optimal intervention strategies in the case of metro system failures," International Journal of Transport Development and Integration, vol. 1, no. 1, pp. 63-73, 2017. 


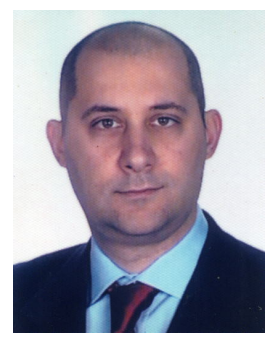

Luca D'Acierno is Associate Professor at Federico II University of Naples, Italy. He holds an MSc degree in Civil Engineering (2000) and a $\mathrm{PhD}$ in Road Infrastructures and Transportation Systems (2003), both from Federico II University of Naples, Italy. His research interests include public transport planning and design, rail system analysis and management, multimodal transportation network design, transportation network assignment, pricing policy analysis, and probe vehicle use. He has authored more than 130 papers in peer-reviewed journals and conference proceedings.

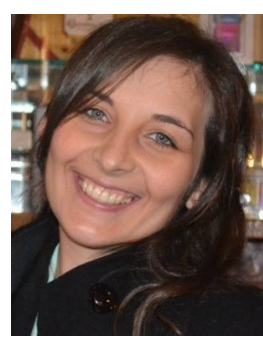

Marilisa Botte is a $\mathrm{PhD}$ student in Civil System Engineering at Federico II University of Naples, Italy, having completed her MSc in Hydraulics and Transportation Systems Engineering (2014) at the same university. Her research interests include rail system analysis and management, and travel demand estimation. She has authored 15 papers in peer-reviewed journals and conference proceedings.

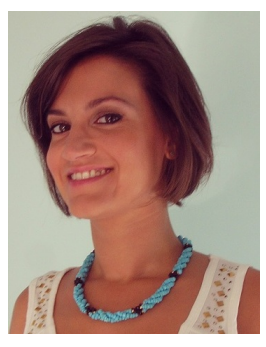

Claudia Di Salvo is Materials Planner at GE Oil\&Gas (Italy) and research collaborator at Federico II University of Naples. She holds an MSc degree in Civil and Environmental Engineering (2012), and has completed postgraduate training for experts in Digital Pattern techniques (2014), both at Federico II University of Naples, Italy. Her research interests include signalling system analysis, longterm travel demand estimation and rail system simulation. Moreover, she has authored five papers in peer-reviewed journals and conference proceedings.

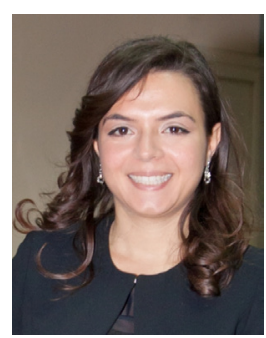

Chiara Caropreso is a scholarship holder at the Department of Civil, Architectural and Environmental Engineering, Federico II University of Naples where she was awarded an MSc degree in Hydraulics and Transportation Systems Engineering in 2016. Her research interests include rail system simulation and long-term travel demand estimation. Moreover, she has authored two papers in conference proceedings.

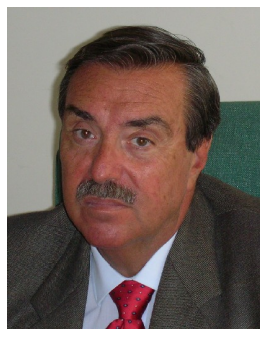

Bruno Montella is Full Professor at Federico II University of Naples, Italy. $\mathrm{He}$ holds an MSc degree in Transportation Engineering (1973) from the same university. His research interests include transit system analysis and management, multimodal transportation network design and optimisation, and public transport quality. He has authored more than 170 papers in peerreviewed journals and conference proceedings. 